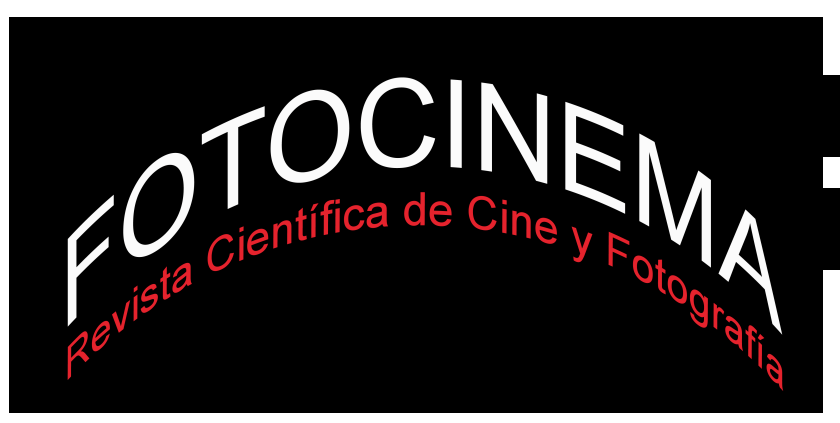

\title{
LA DESINTEGRACIÓN DEL SUEÑO AMERICANO EN EL CINE DE MARTIN SCORSESE
}

\section{THE DISINTEGRATION OF THE AMERICAN DREAM IN MARTIN SCORSESE'S CINEMA}

\author{
Pablo Salvador Gómez Gil \\ Universidad Rey Juan Carlos \\ psgomezgil@gmail.com
}

\section{Resumen:}

El presente estudio recorre la obra del cineasta Martin Scorsese con el objeto de revelar una de sus principales constantes creativas: la negación del Sueño Americano como una posibilidad al alcance de cualquier estadounidense, independientemente de su condición social o su procedencia. Desde los matones callejeros hasta los triunfadores devorados por el éxito, los protagonistas del cine de Scorsese rompen con este mito y deben conformarse con una realidad que únicamente les conduce al fracaso. Un sueño del que el realizador, nieto de unos inmigrantes llegados a América en busca de una vida mejor, muestra el lado más desconocido y cruel a través de sus películas. En ellas, el ideal de prosperidad se convierte en una meta inalcanzable para la mayoría de los personajes, y en una fuente de codicia y locura para los pocos que logran disfrutarlo. Sin embargo, Scorsese compensa esta visión desesperanzada ofreciendo una vía de redención a sus protagonistas de mayor entereza moral, al tiempo que condena a los más viles y corruptos a una existencia solitaria.

\begin{abstract}
:
This study reviews Martin Scorsese's work in order to reveal one of his main creative features: denial of the American Dream as a possibility within any citizens' reach, regardless of their social status or origin. From street thugs to winners absorbed by success, Scorsese's main characters break with the latter myth and must conform to a reality that only leads them to failure. A dream from which the director, who is the grandson of immigrants that moved to America in search of a better life, shows the most unknown and cruel side through his movies. The ideal of prosperity in his films turns into an unattainable goal for most of the characters, whilst becoming a source of greed and madness for the few that manage to enjoy it. However, Scorsese compensates this hopeless vision by providing a route to redemption to characters with greater moral fortitude, while condemning the most vile and corrupt to a solitary existence.
\end{abstract}

\section{Palabras clave:}

Martin Scorsese; sueño americano; Little Italy; redención; cine.

Keywords:

Martin Scorsese; American Dream; Little Italy; redemption; cinema. 


\section{Introducción}

La idea de que cualquier ciudadano de Estados Unidos puede alcanzar la prosperidad y el éxito independientemente de su condición social y su procedencia se recogía ya en la Declaración de Independencia de 1776, si bien la expresión Sueño Americano no sería acuñada hasta 1931 por James Truslow Adams en su libro The Epic of America. En él, el escritor e historiador definía el término como "una característica típicamente norteamericana (...) El sueño de una vida mejor, más rica y feliz, para todos nuestros ciudadanos sin importar su clase” (Adams, 2012, p. XIX, XX), afirmación según la cual hasta el hombre más pobre podía convertirse en un ejemplo de superación si residía en la tierra de la libertad. De este modo, muchas personas de diferentes razas, culturas y nacionalidades, convencidas de no encontrar nunca esa bonanza en sus lugares de origen, decidieron viajar a América en busca de una oportunidad para ellas y para sus familias (Cabezuelo, González \& Fanjul, 2013, p. 4).

El abuelo de Martin Scorsese, Francesco, fue uno de ellos. Natural de Polizzi Generosa, un pueblo cercano a Palermo (Sicilia), trabajó en una granja hasta los diecinueve años, momento en que decidió probar suerte en la utopía americana. En 1900 desembarcó en Nueva York, donde ejerció oficios tan diversos como vendedor de frutas y legumbres u obrero de los astilleros. Allí también conoció a Teresa, una joven de su mismo pueblo con la que se acabaría casándose poco después. El ansiado bienestar económico, sin embargo, no llegó nunca, y Francesco, como la mayoría de los inmigrantes italianos que cruzaron el Atlántico en busca de fortuna, jamás abandonó su condición humilde. Su hijo Charles, padre de Martin, no correría distinta suerte, ganándose la vida como planchador de pantalones mientras su esposa, Catherine, pasaba horas haciendo costura en una fábrica. Con el tiempo, el propio Scorsese les ofreció la posibilidad de prosperar contratándoles para sus películas: a su padre como miembro del equipo de vestuario a y su madre como proveedora oficial de comida. A ambos les 
dedicaría un documental, Italianamerican (1974), donde exploraría sus raíces sicilianas.

En cierto modo, el barrio de Little Italy, en Manhattan, representaba la frustración del Sueño para el colectivo italiano. Sus primeros habitantes habían llegado a principios del siglo $\mathrm{XX}$ con un deseo imposible de materializar, algo de lo que solo pudieron ser conscientes transcurridos algunos años, ya con varias bocas que alimentar a su cargo. Como si pretendieran mostrar su rechazo a un ideal y a la nación que lo había proclamado, estos inmigrantes pasaron a conformar una comunidad cerrada donde nadie hablaba en inglés y en la que se regían según sus normas. Según recuerda Scorsese, "Elizabeth Street era básicamente siciliana, como mis abuelos, y allí la gente tenía sus propias leyes. No nos importaban nada el gobierno, la policía o los políticos; pensábamos que teníamos nuestro propio sistema” (Thompson \& Christie, 1999, p. 23).

Este espíritu desobediente derivó, necesariamente, en un auge de la delincuencia callejera, las bandas y el crimen organizado, un ambiente hostil que el joven Scorsese se veía obligado a experimentar día tras día:

En Little Italy, donde vivíamos, el miedo se había erigido en sistema de vida, o de supervivencia. Nuestro entorno era muy violento. Ahí yo he visto de todo, la más inmunda miseria (...) Todo eso, para un muchacho de ocho años, es más bien espantoso. $\mathrm{Y}$ seguramente algo de eso queda. Indeleblemente. Por otra parte, más que la reacción de un chico, el reflejo primitivo de defensa es la huida. Un chico que tiene miedo corre. Y yo jamás he podido correr, porque era asmático (Monterde, 2000, p. 24).

La enfermedad, por tanto, limitaba su ejercicio físico y su deseo, cada vez mayor, de abandonar Little Italy. Fue entonces cuando Scorsese, todavía un niño, comenzó a frecuentar las salas de cine acompañado de su padre. Ellas constituían su particular refugio: por un lado, le mantenían entretenido mientras se protegía del duro invierno neoyorquino; por otro, le hacían sentirse a salvo de los matones y trapicheros que se movían por el barrio. Y fue así, casi por casualidad, como Scorsese huyó hacia los mundos lejanos y fantásticos que se sucedían ante sus ojos, una evasión que se consumaría 
cuando, siendo ya un adolescente y recuperado de su asma, se desplazaba de un lado a otro de la ciudad en busca de un cine donde se proyectaba un título concreto que estaba ansioso por descubrir (Monterde, 2000, p. 24). Lo que vino a continuación es de sobra conocido: Scorsese ingresó en la NY Film School y acabó convirtiéndose en uno de los cineastas más importantes de su generación, además de un hombre tremendamente rico. Paradójicamente, el nieto enfermizo de unos inmigrantes italianos alcanzó el Sueño Americano sin pretenderlo, después de huir de un lugar que representaba la cara más amarga de ese deseo de riqueza y prosperidad. En su pensamiento el ideal era posible, pero solo para aquellos que no vivían obsesionados con él: "Al construir su obra alrededor de las ilusiones y las trampas del Sueño Americano de todos los inmigrantes, Scorsese forjó su destino" (Sotinel, 2010, p. 5).

Esta reflexión recorre la mayor parte de las obras de Scorsese. En ellas, los protagonistas, como en su día hicieran los antepasados del realizador, persiguen a toda costa una vida mejor hasta el punto de conformar su única razón de ser, si bien tanta obcecación solo les conducirá al fracaso. Por el camino, nunca llegarán a saborear el éxito, y si lo hacen, la caída será rápida y dolorosa.

\section{Marco teórico y metodología}

El objetivo de la presente investigación consiste, pues, en verificar si dicha tendencia responde a una expresión de la intimidad del cineasta a partir de los recuerdos de juventud y de su propia experiencia, circunstancia que reforzaría todavía más su ya contrastada consideración de autor entre los estudiosos de su obra. Para ello, realizaremos un análisis de los protagonistas partiendo del modo en que la búsqueda de la absoluta felicidad afecta a sus personalidades y sus vidas.

Estos personajes estarán clasificados en tres grupos, en función de las diferentes visiones que Scorsese tiene del Sueño Americano: 
- Personajes de posición humilde que persiguen un Sueño que nunca llega a materializarse (relacionado con el recuerdo de sus abuelos y sus padres).

- Personajes de posición humilde que persiguen el Sueño a través del crimen y la delincuencia (relacionado con su entorno en Little Italy).

- Personajes de posición humilde que alcanzan el Sueño pero corren el riesgo de perder el control y derrumbarse (relacionado con su experiencia entre 1976 y 1978, cuando su carrera estuvo a punto de hundirse por una depresión y la adicción a las drogas).

El estudio comprenderá el grueso de largometrajes firmados por Scorsese, a excepción de aquellos títulos cuya acción no tiene lugar en Estados Unidos ni cuentan con personajes norteamericanos -La última tentación de Cristo (The Last Temptation of Christ, 1988), Kundun (1997) y La invención de Hugo (Hugo, 2011)-, si bien en todos ellos están presentes otros temas recurrentes de su autor, tales como la religión, en el caso de los dos primeros (el director neoyorquino sopesó muy seriamente el sacerdocio durante sus años en Little Italy), o el amor por el cine y sus orígenes, en el caso del tercero ${ }^{1}$.

\subsection{Perseguidores de un sueño imposible}

El recuerdo de Francesco, y por extensión el de sus propios padres, ha acompañado siempre a Scorsese y a muchos hombres y mujeres de su cine, los cuales intentan escapar de sus alienantes existencias y lograr la notoriedad que su humilde procedencia parece haberles negado. Nacidos en el seno de familias pobres, estos personajes tratarán de sobreponerse a sus penurias económicas mostrando una fe inquebrantable en el Sueño Americano, con la única salvedad de los nobles y bien considerados protagonistas de La edad de la inocencia (The Age of Innocence, 1993), la adaptación que Scorsese hizo de la novela de Edith Wharton. En esta

\footnotetext{
${ }^{1}$ Del mismo modo, dejaremos al margen de la investigación las películas documentales que Scorsese ha dedicado a otra de sus grandes pasiones: la música. Nos referimos a El último vals (The Last Waltz, 1978), No Direction Home: Bob Dylan (2005), Shine a Light (2008) y George Harrison: Living in the Material World (2011).
} 
película, sin embargo, la quimera estadounidense se aprecia en la figura de Newland Archer (Daniel Day-Lewis), quien se rebela contra su destino y un matrimonio concertado por el amor que siente hacia la condesa Olenska (Michelle Pfeiffer), una mujer de ideas liberales que viaja al Nueva York de 1870 para poder divorciarse de su marido, algo inconcebible en el lugar de donde procede. Scorsese, como Wharton, "evoca el ambiente de un sistema social aferrado a sus tradiciones, que se rige por una serie de códigos y que se traducen en un comportamiento restrictivo, revelando las contradicciones que en él anidan” (García Ruiz, 2010, p. 103).

Los perdedores de Scorsese, más allá de los apuros económicos, se ven obligados a enfrentarse a traumas, fracasos sentimentales y pérdidas de seres queridos, además de a un terrible sentimiento de culpa que les acompaña desde hace tiempo. La fortuna les es adversa, y, sin embargo, no se trata de personajes antipáticos que endurezcan su carácter y decidan apartarse de un mundo que les trata con hostilidad. Incluso el Travis Bickle (Robert De Niro) de Taxi Driver (1976) tiene un sentimiento altruista con la joven prostituta a la que quiere rescatar de las calles. Solo así se convertirá en el héroe que siempre quiso ser: "En cada calle, en cada ciudad, hay un don nadie que sueña con ser alguien”, rezaba una de las frases promocionales del film (Müller, 2005, p. 196). En ocasiones, este buen fondo viene acompañado de un talento natural en el que basan sus escasas posibilidades de éxito; a diferencia de los protagonistas del siguiente grupo (los delincuentes y mafiosos), estos personajes conservan ciertos valores y buscan prosperar sin sobrepasar los límites de la legalidad y trabajando en aquello para lo que se sienten más capacitados.

Scorsese, reconocido amante de la música -en especial del jazz y el rock'n'roll-, retrata en Alicia ya no vive aquí (Alice Doesn't Live Here Anymore, 1974) a un ama de casa que quiere hacer carrera como cantante tras la muerte de su marido, mientras el protagonista de New York, New York (1977) sueña con convertirse en un saxofonista de éxito en los años posteriores a la Segunda Guerra Mundial. De igual modo, El color del dinero (The Color of Money, 1986) presenta a un ex campeón de billar en horas 
bajas que hace valer sus dotes sobre el tapete para instruir a una joven promesa y regresar él mismo a la competición, provocando que "los esfuerzos de los jugadores por alcanzar la excelencia se comparen, como el título sugiere, con la búsqueda de dólares” (Cashmore, 2009, p. 27). Todos ellos persistirán en su empeño a pesar de los infortunios presentes en el camino, sin igualar, claro está, el cúmulo de desgracias que ilustran el viaje nocturno de Paul Hackett (Griffin Dunne) en iJo, qué noche! (After Hours, 1985), narrado por Scorsese con unas dosis de ironía y humor negro que lo alejan del realismo y la amargura que se desprendían de los tres títulos anteriores.

La posibilidad de que cualquier ciudadano de Estados Unidos pueda convertirse en un héroe o una estrella de los medios de comunicación es otra de las variantes del Sueño, si bien en el caso de Scorsese los personajes que manifiestan dicho deseo se obsesionan hasta el punto de desarrollar importantes trastornos psicológicos. En Shutter Island (2010), el agente federal Teddy Daniels (Leonardo DiCaprio) se empeña en desenmascarar a un viejo médico nazi que realiza experimentos en una isla del puerto de Boston, en una época, los años 50, en que el FBI copaba las portadas de los periódicos tras detenciones tan sonadas como las de Bonnie y Clyde, Al Capone o John Dillinger (Weiner, 2012, p. 15). Por su parte, el protagonista de El rey de la comedia (The King of Comedy, 1983), Rupert Pumpkin (Robert De Niro), es un comediante aficionado que sueña con ser algún día tan popular como su ídolo, el artista televisivo Jerry Langford (Jerry Lewis), a quien acosará y acabará secuestrando como única vía para aparecer en su show.

En Taxi Driver, Travis Bickle regresa de Vietnam atormentado por culpa de una promesa incumplida de su gobierno, el mismo que le envió a una guerra para ser un héroe y después le trajo de vuelta para convertirlo en paria: "Una visión paranoica de la Norteamérica de la época, obsesionada por la derrota en Vietnam, las armas de fuego, el aumento de los índices de criminalidad y el fin del Sueño Americano" (Fernández Valentí, 2008, p. 45). El protagonista sigue siendo el mismo individuo anónimo que era antes de partir al frente, solo que ahora convive con el recuerdo de un infierno que le 
impide dormir por las noches. Decidido a reclamar su cuota de popularidad, Travis planificará un atentado contra uno de los candidatos a la presidencia: "Esa condición solitaria es el resultado de la inadaptación inherente a su retorno de la guerra, tanto como consecuencia de los horrores vividos como por la incomprensión de una sociedad que no ha asimilado el alcance del sacrificio" (Monterde, 2000, p. 175). Veintitrés años después de Taxi Driver, Scorsese plantearía en Al límite (Bringing Out the Dead, 1999) una estructura casi idéntica, a través de la figura de Frank Pierce (Nicolas Cage), un paramédico que también es insomne, conduce de noche a través de las zonas más degradadas de Nueva York y vive angustiado por los fantasmas del pasado, aguardando el momento de salvar esa vida que le otorgue, al fin, el reconocimiento y la admiración de los demás. No por casualidad, ambas películas fueron escritas por el mismo guionista, Paul Schrader.

Pese a que ninguno de los protagonistas de este primer grupo verá satisfechos sus anhelos, Scorsese no puede evitar demostrar simpatía hacia ellos y hacia su quimérica travesía existencial, otorgándoles al final de cada relato una posibilidad de redención que, aunque nunca les conducirá hacia el Sueño Americano, sí les proporcionará un estado de felicidad puntual para compensar, en cierto modo, su actitud de entereza ante las dificultades. En $\mathrm{El}$ color del dinero, "Fast" Eddie Felson (Paul Newman), recupera la motivación para volver a ser el campeón de antaño, “alguien que necesita volver a creer en sí mismo tras haber vivido durante años en el ostracismo" (Fernández Valentí, 2008, p. 79), mientras en New York, New York Jimmy Doyle (Robert De Niro) es aceptado de nuevo por la mujer a la que abandonó cuando supo que estaba embarazada. De igual manera, el resto de personajes principales encontrarán un resquicio para la esperanza: Travis abandonará su soledad tras liquidar al protector de Iris (Jodie Foster) y ganarse una inesperada popularidad, Frank encontrará el equilibrio necesario después de liberar a un enfermo terminal de su agonía, Paul llegará a tiempo al trabajo para continuar con la rutina una vez superada su odisea nocturna, y Newland Archer tendrá la oportunidad de reencontrarse con la condesa años más tarde de renunciar a ella. Incluso Teddy Daniels será capaz de limpiar su 
conciencia si acepta que mató a su esposa y que en realidad vive recluido en una institución mental.

Estas etapas, sin embargo, no durarán demasiado, pues conocemos bien a los personajes y sabemos que, tarde o temprano, sus demonios particulares aflorarán nuevamente hasta devolverlos a la triste realidad. En El rey de la comedia, por ejemplo, Rupert cumple su propósito de ser una celebridad, aunque todo parece indicar que su inestabilidad psicológica, unida a la fama cíclica de las estrellas de televisión, le hará caer en el olvido en el momento menos pensado. Al final de Alicia ya no vive aquí, Alice (Ellen Burstyn) encuentra la estabilidad al lado del granjero David (Kris Kristofferson), si bien se trata de una ilusión pasajera reconocida por el mismo Scorsese:

Tal vez Burstyn y Kristofferson siguieran juntos el resto de sus vidas, pero sería una relación bastante tormentosa. Había una frase clave, cuando él decía de su primera esposa: "Ella dijo me voy y yo le abrí la puerta". Intenté que esto fuera realista en lo que afectaba a su relación: obviamente, él ocultaba algunas cosas y cuando las dejara salir no iba a ser divertido (Thompson \& Christie, 1999, p. 84).

\subsection{El crimen como vía rápida hacia la gloria}

El segundo grupo de buscadores de fortuna en el cine de Scorsese remite directamente a sus años en Little Italy, donde creció rodeado de matones de poca monta, rateros y capos de la mafia, individuos todos ellos con un objetivo común: enriquecerse al margen de la ley mediante la intimidación y la violencia. Desde la asaltadora de trenes en los años de la Gran Depresión de El tren de Bertha (Boxcar Bertha, 1972) hasta el psicópata asesino con ansias de venganza de El cabo del miedo (Cape Fear, 1991)², han sido muchos los personajes scorsesianos que han hecho de la muerte ajena y el

\footnotetext{
${ }^{2}$ De hecho, la violencia es prácticamente el único elemento personal que Scorsese aportó a El cabo del miedo, uno de sus contados proyectos de encargo que se vio obligado a realizar para Universal Pictures en contraprestación por el apoyo brindado por el estudio años antes, con motivo de la polémica realización de La última tentación de Cristo (Monterde, 2000, p. 411). La película iba a ser filmada inicialmente por Steven Spielberg, razón por la cual Scorsese optó deliberadamente por rodarla de un modo más cercano al estilo de su colega que al suyo propio: "Decidí rodar El cabo del miedo, ese puro producto de estudio (...) a la manera de Spielberg” (Fernández Valentí, 2008, p. 99).
} 
crimen su razón de ser. De hecho, dos de sus trabajos iniciales, Who's That Knocking at my Door? (1969) y Malas calles (Mean Streets, 1973) parten de una premisa común: un muchacho italiamericano -llamado J.R. en la primera película y Charlie en la segunda, e interpretado en ambos filmes por Harvey Keitel- que pasa el tiempo con sus compañeros de pandilla, todos ellos delincuentes con pocas aspiraciones en la vida, y que se debate entre la posibilidad de un futuro mejor fuera de los límites de Little Italy o prosperar entregándose de lleno a los negocios turbios que proliferan por el barrio. Ferreras (2011, p. 112) se refiere así a esta doble vía en el caso concreto de Malas calles:

Uno de los trabajos de carácter más autobiográfico que jamás ha hecho su director (...) Se estructura a base de episodios de la vida cotidiana, monótona y repetitiva, de un grupo de amigos en el barrio de Little Italy durante los años 70: la insularidad de su vida, sin apenas relaciones con el exterior, las horas muertas en el bar, donde siempre se citan, las salidas nocturnas en coche a otras zonas de la ciudad para ir al cine, las peleas con otras pandillas, etc. El mayor protagonismo dentro del grupo lo adquiere Charlie (Harvey Keitel), un joven de profundas creencias católicas que se encuentra atrapado en el filme entre buscar la absolución y permanecer a la derecha se su tío, el mafioso del barrio, que tiene la llave de su futuro profesional.

Durante las décadas siguientes, Scorsese ofrece nuevas historias protagonizadas por jóvenes pertenecientes a familias de inmigrantes que, dedicados a la vida callejera, comienzan a ascender en la organización como protegidos del gánster poderoso. Es lo que sucede tanto en Gangs of New York (2002) como en Infiltrados (The Departed, 2006), donde sendos personajes con raíces irlandesas, Amsterdam Vallon (Leonardo DiCaprio) y Colin Sullivan (Matt Damon) crecen a la sombra de sus respectivos mentores, Bill "El Carnicero" Cutting (Daniel Day-Lewis) y Frank Costello (Jack Nicholson). Una visión común de la degradación del Sueño Americano a través de la violencia, descrita de este modo por Santos (2006) en su crítica de Infiltrados:

La incapacidad de huir de una sociedad que propicia el enfrentamiento y que tan solo deja espacio para el triunfo social a los más corruptos, arroja una 
acerada visión sobre el mundo y la política actual, que Scorsese puntúa maliciosamente situando la bandera norteamericana como fondo de innumerables secuencias cuyo centro es la corrupción y la violencia.

Uno de los nuestros (Godfellas, 1990) se trata, probablemente, de la cúspide mafiosa del cine de Scorsese, y también de la película que mejor refleja lo que significa vivir el Sueño a espaldas de la ley. El protagonista, Henry Hill (Ray Liotta), admira desde niño a los matones de su barrio, liderados por Paul Cicero (Paul Sorvino), lo que le lleva a abandonar sus estudios y a trabajar para el sindicato del crimen desde una edad bien temprana. Con el paso de los años, Henry amasará una considerable fortuna gracias a los negocios fraudulentos, en una clara manifestación del "Sueño Americano Tóxico" (...) Sus resultados no provienen de un trabajo duro y honesto, ni de la perseverancia; la mayoría son como Henry Hill, que siempre quiso ser un gánster, y, cuando finalmente lo logró, solo quería todo aquello que el dinero pudiese comprar" (Cashmore, 2009, p. 28). Fernández Valentí (2008, p. 95) se refiere igualmente al descontrol que, poco a poco, caracteriza al personaje principal:

Uno de los nuestros es el film que mejor resume las cualidades de su autor, y, coherentemente, ofrece un retrato un tanto excesivo de un modo de vida edificado también sobre el exceso (de dinero, de poder, de violencia), contado desde el punto de vista de un personaje seducido por ese mundo desde su juventud y que, a medida que va creciendo, va perdiendo el control sobre sí mismo, poniendo así de relieve la convulsa fragilidad de esa manera de vivir.

La máxima del “dinero llama a dinero" de Uno de los nuestros también constituye la base de Casino (1995), donde la frenética ciudad de Las Vegas simboliza la ambición sin límites de quien se lucra de manera ilícita: "A Scorsese no le interesa la extraordinaria morfología de la ciudad, sino los fundamentos internos de poder que la mantienen, la forma cómo se sostiene y funciona el negocio del juego" (Gorostiza, 1998, p. 35). La película cuenta como un famoso jugador llamado Sam Rothstein (Robert De Niro) recibe el encargo de gestionar un casino controlado por la mafia, adentrándose en una espiral de poder y pecado que le llevará a convertirse en uno de los hombres 
más ricos de la ciudad y en uno de los objetivos del peligroso criminal Nicky Santoro (Joe Pesci), antiguo colaborador suyo.

A diferencia de lo que sucedía con los protagonistas del grupo anterior, ninguno de estos personajes conseguirá ni tan siquiera una redención momentánea: el hecho de haber sacrificado su propia humanidad a cambio de dinero - con el ultraje del Sueño Americano que eso conlleva- les deja sin posibilidad alguna de recompensa. Todos, sin excepción, están condenados a una llevar una existencia desgraciada, o, incluso peor, a pagar con su vida las consecuencias de sus excesos, como les sucede a los villanos y corruptos que aparecen en El cabo del miedo e Infiltrados (por su parte, los jóvenes protagonistas de Malas calles y Gangs of New York acaban gravemente heridos y corren el riesgo de morir más allá de donde concluye la narración). Para el resto, lo único que aguarda es un futuro de soledad: J.R. pierde a la única mujer que le ha amado y se entrega a su fanatismo religioso, Bertha quedará desamparada tras el asesinato de su compañero de correrías, Sam regresará a sus orígenes como apostador deportivo para el hampa y Henry se verá obligado a aislarse del mundo tras delatar a sus compinches y entrar en el programa de protección de testigos del FBI.

\subsection{La caída de los triunfadores}

El caso de Scorsese corrobora la existencia del Sueño Americano: el hijo de un planchador y una costurera de Little Italy que consigue ser uno de los directores más importantes de todos los tiempos. Sin embargo, también vivió en primera persona la cara más amarga de este ideal, aquella que solo es reconocible cuando un triunfador inicia una decadencia progresiva y acaba devorado por su propio éxito. En 1976, Scorsese tenía apenas treinta y cuatro años y su nombre ya era sinónimo de prestigio debido al excelente reconocimiento crítico de cintas como Malas calles, Alicia ya no vive aquí y, especialmente, Taxi Driver. Llevado por el entusiasmo, aceptó ponerse al frente de New York, New York, un lujoso musical presupuestado en 22 millones de dólares, una cifra tan elevada como inusual para las 
producciones de la época. Pero sucedió lo que pocos esperaban: la película fracasó de manera estrepitosa en taquilla, sumiendo al director en una profunda depresión que, unida al divorcio de su segunda esposa, a la reaparición del asma y a una creciente adicción a la cocaína, le condujo hasta el pabellón de urgencias del Hospital de Nueva York: "Empecé a drogarme demasiado. Vivía a cien por hora y estuve a punto de destruirme por completo (...) Me encerré dentro de mí mismo y me dije: Larguémonos, vayámonos directos al infierno y veamos qué pasa (Fernández Valentí, 2008, p. 52). Scorsese presentaba una hemorragia interna, consecuencia de una mezcla de sus medicinas para el asma y cocaína en mal estado, y manifestaba unas claras tendencias suicidas: "Faltó poco para morir en el curso de esos cuatro días, los más terribles de mi vida” (Dougan, 1997, p. 60).

Durante el período de convalecencia en el hospital, Scorsese recibió la visita de Robert De Niro, quien se presentó convencido de tener entre manos el proyecto adecuado para relanzar la carrera de su amigo y colaborador. Se trataba de una película basada en las memorias del ex campeón mundial de los pesos medios Jake La Motta, papel que el propio De Niro estaba dispuesto a interpretar: "Si le dije que sí a Bobby fue porque, inconscientemente, me identificaba con Jake” (Dougan, 1997, p. 60). En efecto, el proceso de Toro salvaje (Raging Bull, 1980) llevaba tres años en marcha, pero Scorsese, bastante escéptico con sus posibilidades cinematográficas, había rechazado todos los guiones redactados hasta entonces (Thompson \& Christie, 1999, p. 110). Sin embargo, fue esta etapa de crisis personal y profesional la que le llevó a comprender la tragedia de La Motta, alguien que, como él, alcanzó la cima del éxito para después sucumbir irremediablemente a sus demonios interiores.

Toro salvaje comprende veintitrés años de la vida de La Motta, desde sus comienzos sobre el ring hasta su época como monologuista, ya en plena decadencia física y económica. Entre tanto, Scorsese retrata su ascenso a la gloria pugilística, desde donde iniciará un peligroso declive donde tendrán cabida los amaños, las detenciones por corrupción de menores, los malos tratos con su esposa o el enfrentamiento con su propio hermano. El director, 
todavía muy mermado físicamente al comienzo del rodaje, decidió entregarse por completo al proyecto aunque ello le costara la vida: "El propio Scorsese no se ha recatado en absoluto en reconocer el papel terapéutico que le significaba una película hecha auténticamente a tumba abierta, hasta el punto de creerse que pudiera ser la última de su carrera” (Monterde, 2000, p. 254). El efecto que el film tuvo en la faceta artística y personal del cineasta fue justo el contrario, reportándole su primera candidatura al Óscar y devolviéndole al lugar de privilegio que ocupaba justo después de Taxi Driver.

A lo largo de su trayectoria posterior, Scorsese firmaría otros dos biopics ambos protagonizados por Leonardo DiCaprio- que, como en el caso de Toro salvaje, estarían centrados en personajes reales cuyas carreras experimentaron ascensos meteóricos y caídas rotundas. El primero de ellos, El aviador (The Aviator, 2004), ilustraba los años de gloria de Howard Hughes, productor y director de Hollywood y magnate de la aviación, hasta desembocar en un severo trastorno obsesivo-compulsivo que le llevaría a recluirse en su mansión y a abusar de toda clase de drogas y medicamentos. Pese a que los orígenes de Hughes no fueron precisamente modestos - su padre era un acaudalado industrial de la prospección petrolífera-, sí es cierto que, tras dilapidar la herencia de su familia en la película Los ángeles del infierno (Hell's Angels, 1930) y verse prácticamente en la ruina, supo reconstruir su imperio hasta convertirse en uno de los hombres más poderosos del planeta (Barlett \& Steele, 2011, p. 11).

El protagonista de El lobo de Wall Street (The Wolf of Wall Street, 2013), Jordan Belfort, comparte con Jake La Motta la procedencia humilde y las peleas domésticas con su esposa, y con Howard Hughes la debilidad por las sustancias alucinógenas y las bellas mujeres. Con apenas veinte años, Belfort fundó su propia agencia bursátil, y poco después ya era uno de los brokers más despiadados de Wall Street; poseído por una codicia sin límites, no tardó en entregarse a una vorágine de sexo, drogas y blanqueo de capitales que acabaría llevándole a la cárcel. Muchos vieron en él la personificación del 
Sueño Americano, y es precisamente en esta percepción errónea del término donde Scorsese centra su crítica:

La codicia de Belfort o los veintiún millones que era capaz de amasar en tres horas en sus mejores jornadas son el tipo de cosas que no solo están bien vistas por la sociedad en que vivimos, sino que muchas veces se nos marcan como objetivos a conseguir (Bernal, 2014, p. 81).

El director ofrece a este trío de triunfadores caídos en desgracia una opción redentora a mitad camino entre los personajes del primer grupo y los del segundo: si bien nunca disfrutarán de una felicidad puntual, pues su comportamiento dista en muchas ocasiones de ser ejemplar, se les brindará la oportunidad de comenzar una nueva vida más sencilla y menos problemática, alternativa que Scorsese nunca contempló para sus protagonistas más viles. De este modo, al final de sus respectivos relatos, Jake La Motta se gana la vida recitando monólogos en un hotel de Nueva York, Howard Hughes mantiene su influencia delegando muchas más responsabilidades en sus colaboradores y Jordan Belfort se recicla como orador motivacional tras cumplir su condena.

\section{Conclusiones}

Durante sus cuarenta y cinco años de trayectoria tras la cámara, Martin Scorsese se ha consolidado como uno de los mejores retratistas cinematográficos del Sueño Americano y sus consecuencias. Su obra capta como pocas la idiosincrasia de un concepto que ha sabido representar, mejor que cualquier otro, el ideal de libertad, igualdad y progreso de Estados Unidos desde su constitución como país. Sin embargo, Scorsese, tercera generación de una familia de inmigrantes italianos, ha mostrado el Sueño según su propia perspectiva, como una posibilidad real para unos cuantos elegidos pero inalcanzable para el resto, condenados a estrellarse tarde o temprano contra un infranqueable muro de realidad. Serán precisamente estos últimos los que llamen la atención del realizador, personajes cuyas ambiciones acabarán frustrándose como en su día sucedió con las de su abuelo, Francesco Scorsese. Una visión cruda y sin contemplaciones del 
Sueño que, en su caso, se hace extensiva a aquellos que deciden forjar su propio camino hacia el éxito a través de la violencia y crimen -consecuencia directa de los años en Little Italy entre mafiosos de toda índole-, y también a celebridades del cine, el deporte o las finanzas que acabaron pagando un alto precio por sus excesos, una situación que no resulta ajena al propio Scorsese.

Aunque a todos los protagonistas les aguarda un futuro desalentador, cada uno de ellos recibirá una justa recompensa al final de sus respectivas historias. Los individuos honrados y trabajadores, fiel reflejo de los abuelos y los padres del director, encontrarán motivos para esperanza que, aunque pequeños, les ayudarán a sobreponerse de sus problemas. En cambio, los que hacen de la corrupción su forma de vida acabarán muertos o desamparados como castigo por sus crímenes, mientras aquellos triunfadores que se ven abocados al vacío por culpa de los abusos gozarán de una última oportunidad para resarcirse. En otras palabras, la redención constituye uno de los temas capitales de la filmografía de Scorsese, si bien cada personaje la experimentará en función de su actitud ante el Sueño Americano.

Por primera vez desde 1997, Scorsese abandonará territorio norteamericano en su siguiente proyecto, Silence, adaptación de la novela del mismo título escrita por el Shusaku Endo sobre la aventura evangelizadora de dos monjes jesuitas en el Japón del siglo XVII. Sin embargo, aunque aparque momentáneamente su visión crítica de la sociedad norteamericana, esta impresión desalentadora de la "Tierra Prometida" sigue y seguirá muy presente en Hollywood. Pese a encontrarse todavía en activo, existe un grupo de cineastas más jóvenes que no ocultan el enorme legado de Scorsese en su obra, un hecho que no hace sino engrandecer su ya legendaria figura. Nombres como David O. Russell, James Mangold, James Gray, Abel Ferrara, Richard Linklater, Paul Thomas Anderson, Wes Anderson o Spike Lee -a quien Scorsese produjo en su día Camellos (Crockers, 1995)- deben buena parte de su prestigio a la influencia del realizador neoyorquino en sus trabajos. El propio Russell, por ejemplo, no dudó en reconocer a Scorsese como la referencia principal a la hora de rodar su película más reciente, $L a$ gran estafa americana (American Hustle, 2013), para la que incluso logró 
que Robert De Niro recuperase al icono mafioso que él mismo popularizó en cintas como Uno de los nuestros o Casino: "Es imposible imitar a Marty, pero también es imposible no citarle y querer parecerse a él cuando estás hablando de casinos, de mafiosillos, de Atlantic City o de las malas calles de Nueva York” (Fernández, 2014, p. 80).

\section{Referencias bibliográficas}

Barlett, D.-L. \& Steele, J.-B. (2011). Howard Hughes: His Life and Madness. Nueva York: W. W. Norton \& Company.

Bernal, M. (2014). El color del dinero. Estreno de El lobo de Wall Street. Fotogramas (2.043), pp. 80-82.

Cabezuelo, F., González, C. \& Fanjul, C. (2013). Los paisajes del Sueño Americano: Escenografía de Mad Men. Revista de Comunicación de la SEECI (32), 1-11.

http://www.seeci.net/revista/index.php/seeci/article/view/19/pdf_5. ISSN 1576-3420.

Cashmore, E. (2013). Martin Scorsese's America. Nueva York: John Wiley \& Sons.

Dougan, A. (1997). Martin Scorsese. The Making of His Movies. Londres: Orion Media.

Fernández, F. (2014). Delitos y faldas. Estreno de La gran estafa americana. Fotogramas (2.044), pp. 78-81.

Fernández Valentí, T. (2008). Martin Scorsese: Un infiltrado en Hollywood. Barcelona: Carena.

Ferreras, J.-G. (2011). Santos seculares: El debate religioso en el cine de Martin Scorsese. Revista Frame (7), 110-123.

http://fama2.us.es/fco/frame/frame7/estudios/1.5.pdf. ISSN 1988-3536

García Ruiz, S. (2010). Polinización transtextual en La edad de la inocencia. Revista Fotocinema (1), 101-121.

http://www.revistafotocinema.com/index.php?journal=fotocinema\&page=a rticle\&op=viewFile\&path\%5B\%5D $=46 \&$ path $\% 5 B \% 5 \mathrm{D}=31$. ISSN 21720150

Gorostiza, J. (1998). Casino / Tener y no tener. Barcelona: Libros Dirigido/Programa Doble.

Monterde, J.-E. (2000). Martin Scorsese. Madrid: Cátedra.

Müller, J. (ed.) (2005). Lo mejor del cine de los 7o. Madrid: Taschen. 
Santos, A. (noviembre de 2006). Infiltrados: Frente al espejo. Miradas de Cine. Recuperado el 23 de febrero de 2013 de http://www.miradas.net/2006/n56/criticas/infiltrados2.html.

Sotinel, T. (2010). Maestros del cine: Martin Scorsese. París: Cahiers du cinéma.

Thomspon, D. \& Christie, I. (eds.) (1999). Martin Scorsese por Martin Scorsese. Barcelona: Alba.

Weiner, T. (2012). Enemigos: Una historia del FBI. Barcelona: Debate.

Cómo citar: Gómez Gil, P. S. (2014). "La desintegración del Sueño Americano en el cine de Martin Scorsese”. Fotocinema. Revista científica de cine y fotografía, 9, pp. 237-254. Disponible:

http://www.revistafotocinema.com/index.php?journal=fotocinema 